\section{A história de sorte de Londrina com a fotografia}

\section{La história de la suerte de la ciudad de Londrina con la Fotografía}

Paulo César BONI ${ }^{1}$

Resumo: Este artigo trata da história da fotografia em Londrina, cidade do norte do estado do Paraná, e de sua importância para a recuperação de dados históricos e para a preservação da memória da cidade. Por um viés inédito, narra dois momentos de sorte de Londrina com relação à fotografia. O primeiro foi o de sua utilização como estratégia de publicidade da Companhia de Terras Norte do Paraná, responsável pelo empreendimento imobiliário que deflagrou o processo de colonização no norte do Paraná; o segundo foi o da imigração estrangeira, pois os estrangeiros chegavam profissionalmente capacitados para o exercício de ofícios especializados, entre eles o da fotografia. Estes dois lances de sorte propiciaram a produção de fartos registros fotográficos que documentam os primórdios da história de Londrina.

Palavras-chave: História de Londrina (PR). História da fotografia em Londrina. Companhia de Terras Norte do Paraná. Fotografia e Memória.

Resumen: Este artículo trata de la história de la fotografía en Londrina, una ciudad ubicada en el Norte de la Província brasileña de Paraná, y de su importancia para la recuperación de datos históricos y para la preservación de la memória del lugar. Por medio de una mirada original, el texto cuenta dos momentos de Londrina en su relación con la Fotografía. El primero fue su uso como estrategia publicitaria de la Companhia de Terras Norte do Paraná, responsable por el proyecto que desencadenó el proceso de colonización del Norte de la Província. El segundo instante fue la inmigración extranjera, ja que los de otras naciones llegavan bien capacitados profesional-

1 Doutor em Ciências da Comunicação pela Universidade de São Paulo (USP). Líder do Grupo de Pesquisa Comunicação e História do Conselho Nacional de Desenvolvimento Científico e Tecnológico (CNPq). Coordenador do Curso de Especialização em Fotografia: Práxis e Discurso Fotográfico da Universidade Estadual de Londrina (UEL). Editor da revista Discursos Fotográficos. E-mail: discursosfoto@, uel.br mente para el ejercicio de oficios especializados, como la capacidad de fotografar bien. Esos dos eventos fueron la base de una gran producción de registros fotográficos que documentan la historia del início de Londrina

Palabras clave: História de Londrina. História de la Fotografía en Londrina. Companhia de Terras Norte do Paraná. Fotografia y memória.

\section{O início da colonização do norte do Paraná}

Até as duas primeiras décadas do Século XX, a região norte do estado do Paraná, especialmente a área que se estende de Jataizinho (à época Jatahy), às margens do rio Tibagi, à divisa com os estados de São Paulo e Mato Grosso do Sul e com o Paraguai, na extremidade oeste do estado, delimitadas pelos rios Paranapanema e Paraná, era uma imensa área virgem de Mata Atlântica. O governo sabia da necessidade premente de ocupar esta área para garantir a extensão territorial do estado, mas isso exigiria tempo, estratégias de ocupação e, principalmente, investimentos. Ou seja, na essência, por falta de recursos para investimento neste projeto, o norte do $\mathrm{Pa}$ raná permaneceria desocupado.

Esta realidade começou a mudar quando uma comissão de investidores do Reino Unido, denominada Missão Montagu, visitou o Brasil em busca de oportunidades de investimentos. O maior interesse dos componentes dessa missão era o algodão, matéria prima essencial para movimentar a emergente indústria inglesa, neste momento trabalhando a todo vapor por conta da Revolução Industrial. Um de seus integrantes, Lord Lovat, visitou o norte do Paraná (região hoje denominada como Norte Pioneiro) a convite de fazendeiros cafeicultores que estavam, por conta própria, construindo uma estrada de ferro entre Ourinhos (SP) e Cambará (PR), para garantir o escoamento da safra até o porto de Santos (SP).

Lovat ficou impressionado com o potencial produtivo da região e começou a costurar um projeto que despertasse o interesse de investidores britânicos na região. Seu projeto seria comprar uma larga extensão de terras na inóspita região norte do Paraná para plantar algodão e lotear a área para a venda de terrenos. Para viabilizar e explorar esse empreendimento, foi criada em 1925, em Londres, a Paraná Plantation Ltd. Na sequência imediata, os investidores britânicos entraram em contato com o governo do estado do Paraná, que respondeu com muito interesse à proposta de compra da área, pois isso significaria a resolução do problema de ocupação que o 
governo vinha postergando há tempos, principalmente em razão da construção da estrada de ferro que cortaria no sentido de leste a oeste a região norte do estado do Paraná. Com as negociações adiantadas, para atender a legislação brasileira, que proibia a venda de terras para estrangeiros, foi criada em São Paulo a Companhia de Terras Norte do Paraná, com 99,86\% do capital social subscrito pela Paraná Plantation Ltd. e $0,14 \%$ de capital nacional. Também para atender a legislação brasileira (Constituição de 1891), a presidência da CTNP teria que ser exercida por um brasileiro. Para tanto, foi nomeado Antônio Moraes Barros. Legislação cumprida, negócios efetivados:

Em dois anos (de 1925 a 1927), a CTNP comprou 515.000 alqueires paulistas de terras (cada alqueire paulista corresponde a $24.200 \mathrm{~m} 2$ ) para dar início ao projeto de colonização. Localizadas entre os rios Paranapanema, Tibagi e Ivaí, a maior parte dessas terras - cerca de 450.000 alqueires eram considerados terras devolutas (desocupadas e desabitadas) - foi adquirida diretamente do governo do estado do Paraná, a preços relativamente baixos. O baixo valor das terras se justificava pelo interesse do governo em ocupar e desenvolver o estado. Para tanto, era necessário desmatar áreas nativas, transformando-as em produtivas, para, com isso, atrair investimentos e desbravadores dispostos a fincar raízes em áreas ainda inóspitas. Outro fator que pesou na negociação foi o compromisso que a compradora assumiu de construir a estrada de ferro que cortaria toda a região, ligando Cambará a Guaíra. (BONI, 2004, p.32).

Negócio fechado, a CTNP deu início, em 1929, ao projeto de colonização da região norte do estado do Paraná. A primeira providência foi enviar para localidade uma caravana, mais tarde historicamente denominada de "caravana dos desbravadores", responsável por demarcar as terras e começar a construir a infraestrutura necessária para que o local pudesse receber seus primeiros compradores de terras. A caravana era chefiada por George Craig Smith, brasileiro, filho de ingleses, à época com apenas 20 anos de idade, e trazia um engenheiro agrimensor, o russo Alexandre Razgulaeff, e um auxiliar de agrimensura, Spartaco Principe Bambi, brasileiro, filho de imigrantes italianos. A presença dos profissionais da agrimensura era imprescindível, pois era preciso dar início ao demorado e exaustivo trabalho de demarcar as terras adquiridas. Também compunham a caravana dois mateiros, Alberto Loureiro e Joaquim Barbosa, empreiteiros responsáveis pelo início da derrubada da mata e pelo início do preparo da terra o cultivo de lavouras. Por fim, um cozinheiro, Erwin Fröhlich, e um auxiliar de serviços, Geraldo Pereira Maia.

George Craig Smith, Alexandre Razgulaeff e Spartaco Principe Bambi partiram de Ourinhos (SP) para Cambará (PR), dia 20 de agosto de 1929, em um caminhão Ford carregado de ferramentas, arreios, utensílios domésticos e mantimentos. Em Cambará, conhecida à época como a "boca do sertão", a caravana foi reforçada pelos trabalhadores braçais (mateiros, cozinheiro e auxiliar de serviços) e seguiu, no velho caminhão Ford, até Jatahy (hoje Jataizinho - PR), por uma estrada de terra que, de tão precária, mais parecia uma "picada" na mata. Jataizinho era o fim da linha. De lá para a localidade onde começavam as terras da CTNP (hoje Londrina), era preciso atravessar o rio Tibagi e seguir os cerca de 20 quilômetros abrindo picadas a foice e facão na mata fechada que cobria a região. $\mathrm{O}$ transporte de carga, a partir de então, passou a ser em lombo de cavalos e burros. Saíram de Jataizinho na madrugada de 21 de agosto de 1929. No final do mesmo dia chegaram ao local que batizaram de Três Bocas, em razão das três nascentes de água que encontraram.

Descarregaram as tralhas, amarraram os animais e, imediatamente, começaram a abrir uma pequena clareira na mata, na qual construíram dois ranchos de palmito, considerados as primeiras habitações de Londrina. George Craig Smith havia trazido uma câmera fotográfica e fez uma tomada da clareira com os ranchos de palmito (Figura 1). Esta fotografia é considerada uma espécie de "certidão de nascimento" de Londrina, pois foi a primeira tomada no local da futura cidade. 
Figura 1 - A primeira fotografia de Londrina

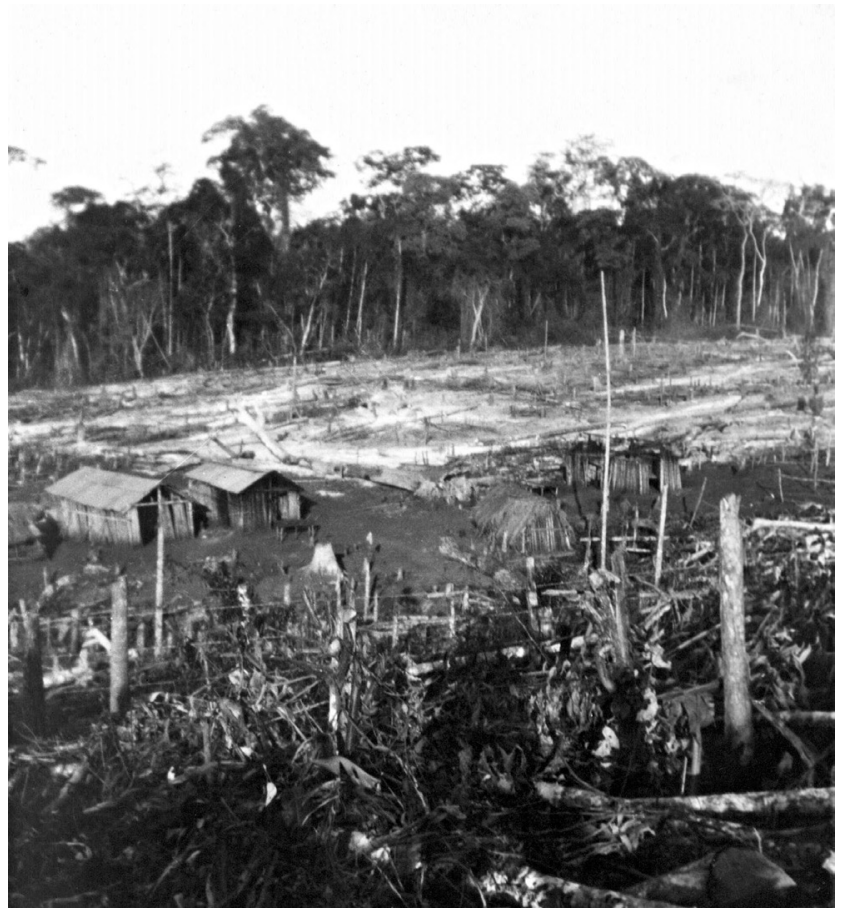

Fotografia: George Craig Smith

Fonte: Acervo do Museu Histórico de Londrina Padre Carlos Weiss

Com a chegada de mais trabalhadores contratados, a CTNP começou a criar a infraestrutura básica, mínima necessária, para receber os interessados em comprar terras na região. Neste sentido, em um primeiro momento, foi preciso abrir uma estrada de transporte rodoviário entre Jataizinho e Londrina, com 22 quilômetros de extensão, para possibilitar a chegada dos compradores; construir um hotel, para hospedar e alimentar os clientes e seus próprios funcionários (Figura 2); e construir um escritório, para gerir o empreendimento e realizar as transações imobiliárias. Em um segundo momento, já com a venda de lotes em andamento, tanto no núcleo urbano quanto na zona rural, foi preciso dar prosseguimento às obras de infraestrutura e, principalmente, dotar o núcleo urbano de alguns serviços, como abastecimento de água, transporte para deslocamentos, fornecimento de energia elétrica, estruturação de serviços de saúde e outros.
Figura 2 - Hotel Campestre, inaugurado em janeiro de 1930

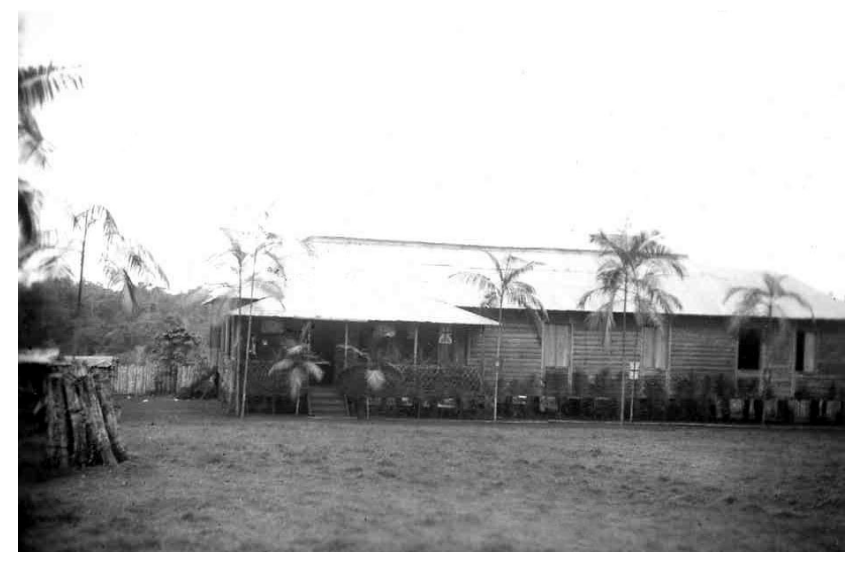

Fotografia: George Craig Smith

Fonte: Acervo do Museu Histórico de Londrina Padre Carlos Weiss

\section{Publicização da CTNP: o primeiro lance de sorte de Londrina com a fotografia}

No início da colonização, fotograficamente falando, Londrina - e, por extensão, toda a região norte do estado do Paraná - teve seu primeiro lance de sorte. A Companhia de Terras Norte do Paraná precisava publicizar seu empreendimento nos estados mais desenvolvidos do país e no exterior para atrair interessados. No Brasil, ela queria atingir potenciais compradores de terras nos estados de São Paulo, Rio de Janeiro, Minas Gerais e Bahia. No exterior, notadamente os países europeus.

Para publicizar o empreendimento, ela adotou a fotografia como principal estratégia de convencimento. Ou seja, os agenciadores (vendedores) de terras que cortavam o país oferecendo "oportunidades de bons negócios" no norte do Paraná levavam consigo um álbum com fotografias que "comprovavam" a fertilidade do solo da região e sua capacidade de resposta rápida às lavouras, com altíssima produtividade. Uma das primeiras fotografias produzidas com este intuito foi a de uma figueira branca, provavelmente centenária, cujo diâmetro do caule era de tamanha dimensão que seria preciso uma dezena de homens com braços abertos e esticados para abraçá-la. Nesta fotografia (Figura 3), tomada por José Juliani, vários homens em pé ou sentados na parte externa de suas raízes servem de referência para que o leitor tivesse uma noção da magnitude da árvore. Outra fotografia bastante utilizada nos álbuns da CTNP foi a de um pioneiro, com indisfarçável ar de satisfação, segurando duas cabeças de repolho de tamanho acima de cabeças de repolho normais (Figura 4). Imagens como estas, à época, eram "documentos comprobatórios" da fertilidade do solo; eram um convite quase irrecusável para investimentos na região. 
Figura 3 - A magnitude da figueira branca atestava a fertilidade do solo...

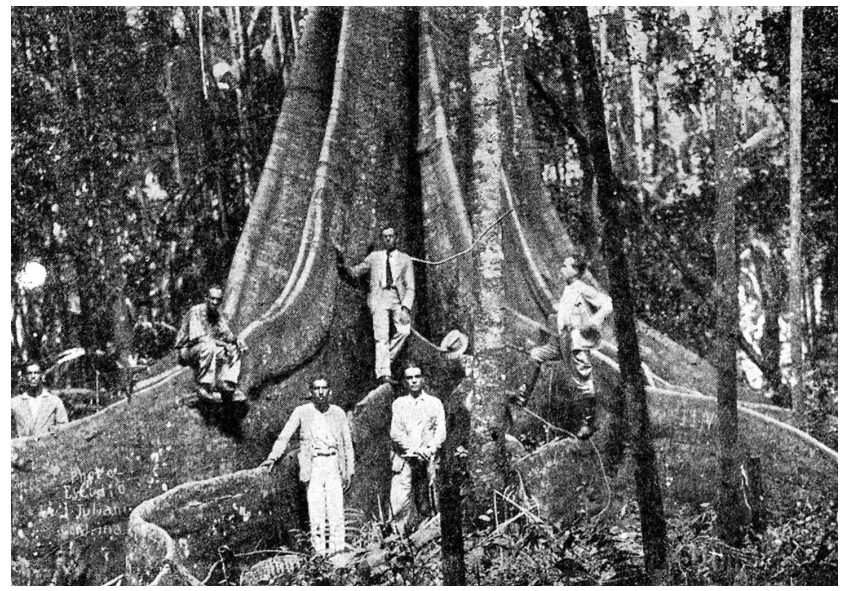

Fotografia: José Juliani

Fonte: Acervo do Museu Histórico de Londrina Padre Carlos Weiss

Figura $4-\ldots$ que, preparado para as lavouras, renderia ótimas colheitas

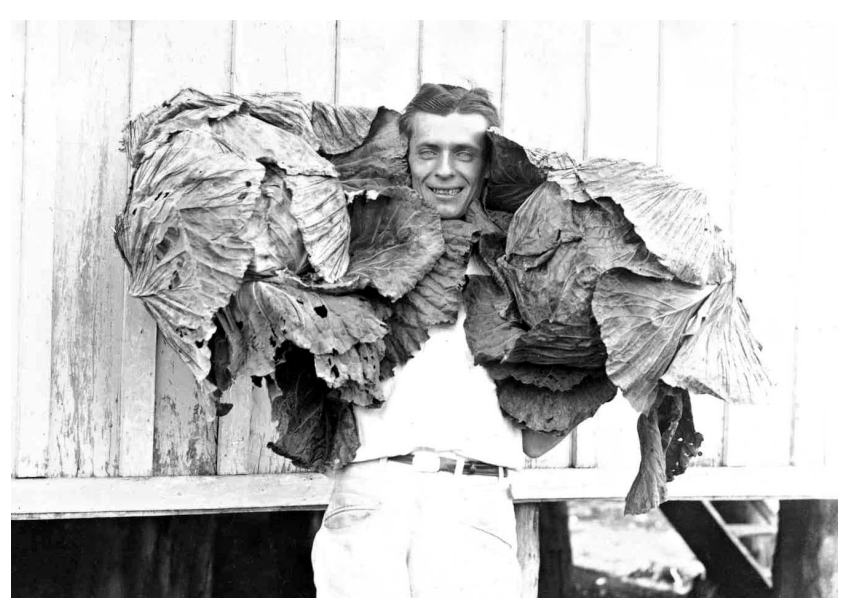

Fotografia: José Juliani

Fonte: Acervo do Museu Histórico de Londrina Padre Carlos Weiss

Para produzir as primeiras imagens de seus álbuns fotográficos, a CTNP contratava fotógrafos, normalmente vindos de São Paulo, para a execução dos serviços. O primeiro dos contratados foi Theodor Preising, fotógrafo alemão, que emigrou para a Argentina em 1920, depois de haver combatido na Primeira Guerra Mundial e, em 1923, trocou a Argentina pelo Brasil, tendo se estabelecido como fotógrafo e vendedor de equipamentos fotográficos em São Paulo. Em 1924 começou a produzir cartões postais das principais cidades brasileiras e a qualidade plástica de seu trabalho chamou a atenção dos diretores da colonizadora, que o contratou para produzir fotografias, "tipo cartão postal", do norte do Paraná. As fotografias de Preising, normalmente retratando famílias instaladas em suas terras (Figura 5) lavouras recém-plan- tadas e o resultado das primeiras colheitas (Figura 6), foram utilizadas como peças publicitárias para vender a imagem de uma região fértil, próspera e, principalmente, promissora. "A formação de lavouras acabou se transformando no grande nicho publicitário. A terra da região era, de fato, muito fértil e assim que as primeiras lavouras começaram a produzir, a produtividade e a qualidade encheram os olhos dos satisfeitos produtores." (BONI; SATO, 2009, p.258).

Figura 5 - Família em sua propriedade rural, produzindo cereais, frutas e verduras

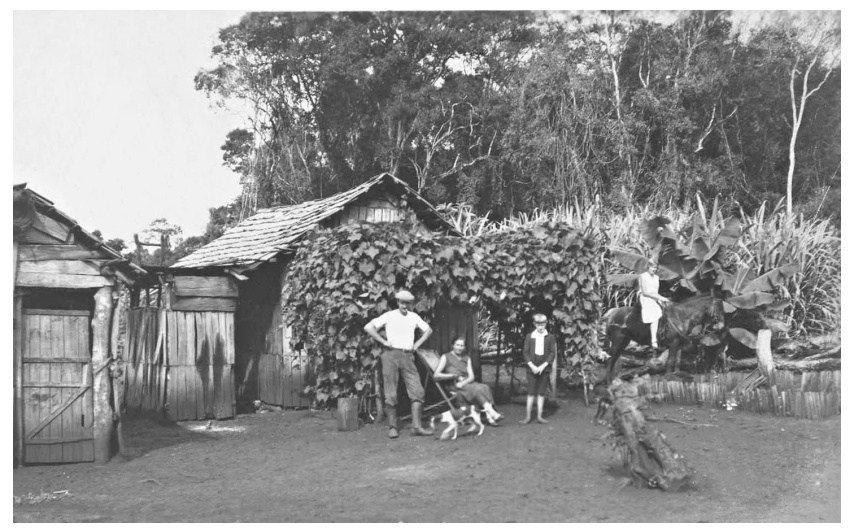

Fotografia: Theodor Preising

Fonte: Acervo do Museu Histórico de Londrina Padre Carlos Weiss

Figura 6 - Resultado da colheita de milho

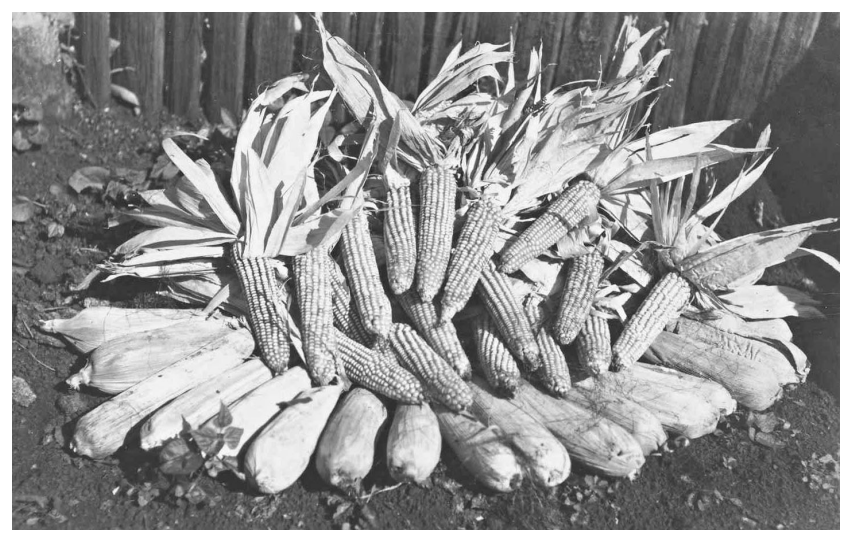

Fotografia: Theodor Preising

Fonte: Acervo do Museu Histórico de Londrina Padre Carlos Weiss

Em suas visitas posteriores, Theodor Preising fotografou a construção de casas residenciais e comerciais, a abertura de estradas, as benfeitorias em chácaras e sítios, a criação de suínos e bovinos e, sempre, os resultados de colheitas. Tudo o que pudesse representar as potencialidades da região e ser utilizado para a criação de um imaginário coletivo de paz, segurança e oportunida- 
des no norte do Paraná era fotografado e criteriosamente utilizado como estratégia de publicização pela CTNP, que, além da ideia de um novo Eldorado e da oportunidade de enriquecimento rápido, vendia sua idoneidade e a segurança do empreendimento, totalmente desembaraçado judicialmente, como "garantia" de bom negócio.

Os vendedores sabiam que a idéia de um Éden terrestre atrairia, afinal de contas, compradores desejosos de adquirir um fragmento do paraíso. [...] Sabiam os vendedores que, em um contexto da vida nacional povoado de conflitos sobre questões de domínio, inclusive no Paraná, a garantia de títulos seguros era um grande atrativo para possíveis compradores. (ARIAS NETO, 1998, p.29).

Garantia de segurança e a visão do Éden. Era exatamente isso que a CTNP queria passar para seus potenciais compradores. A garantia, pela idoneidade da empresa e pelos documentos em ordem do empreendimento; a visão do Éden, pelas fotografias produzidas especificamente para esta finalidade. Ou seja, no processo de desbravamento e colonização do norte do Paraná, a fotografia constituiu-se em uma mídia de fundamental importância.

O segundo fotógrafo, contratado esporadicamente, foi o austríaco Hans Kopp. As informações sobre este importante fotógrafo que, depois de muita peregrinação, radicou-se em Rolândia (PR), onde faleceu e está enterrado, eram poucas e, não raro, imprecisas. Entre 2008 e 2009, Cássia Maria Popolin, então estudante do Mestrado em Comunicação da Universidade Estadual de Londrina descobriu descendentes seus, que guardavam caprichosamente seus documentos e pertences fotográficos (câmeras fotográficas, lentes, negativos de vidro e celulose e muitas fotografias impressas). A partir de então, a história de Hans Kopp e a importância de suas fotografias para a recuperação histórica do norte do Paraná passou a ser recontada, desta feita com precisão, exatidão de detalhes e documentação comprobatória. Porém, as datas de tomada de algumas fotografias ainda continuam imprecisas.

A exemplo de Theodor Preising, Hans Kopp também havia combatido na Primeira Guerra Mundial, experiência que impulsionou sua emigração para o Brasil, pois, durante o conflito, além de matar, passou por muitas agruras e sofrimentos. Decidiu que não queria isso para seus filhos e resolveu emigrar para algum país que não se envolvesse em guerra.

Mas foi a Primeira Guerra Mundial (1914-1918) que mudou o rumo de sua história e marcou sua vida. Em 1917, foi convocado para participar da guerra. Como lança-chamas, viu de perto o horror: morte, destruição e fome. Com o fim da guerra, foi levado preso junto com outros soldados para um campo de concentração na Itália. Enfrentou o rigoroso frio europeu e a fome. Muitos soldados não resistiram e morreram. Todas as manhãs, a mesma cena: corpos de soldados sendo recolhidos e enterrados numa vala comum. (POPOLIN, 2010, p.20).

Hans Kopp, além de fotógrafo era músico, ou seja, sua sensibilidade era duplamente estimulada. Foi um grande fotógrafo de família e cotidiano e um documentador ímpar do crescimento de cidades norte paranaenses, especialmente Rolândia e Londrina, pelo fato de haver introduzido o "registro aéreo" na documentação iconográfica. Não se tratava especificamente de fotografia aérea, mas de uma inovação sua para registros aéreos. Ele subia em árvores para fazer as tomadas. Pregava tábuas no caule para servirem de degraus, como uma escada. No alto da árvore, construía uma plataforma de madeira para apoiar o tripé e a câmera fotográfica. Então, do alto, fazia seus "registros aéreos". Foi uma inovação para a época.

Não há muitas fotografias suas disponíveis no Museu Histórico de Londrina ou no Museu Municipal de Rolândia. Infelizmente, boa parte de seus registros foram entregues aos contratantes de seus serviços e se perderam com o tempo. O acervo recuperado por Cássia Popolin refere-se mais ao que se convencionou chamar "álbum de família", riquíssimo, aliás. De suas imagens de Londrina, provavelmente as mais reproduzidas sejam duas vistas panorâmicas da cidade, tomadas em meados da década de 1930 (Figuras 7 e 8). Sem confirmação oficial, tudo leva a crer que essas duas tomadas tenham sido feitas do alto de árvores.

\section{1}


Figura 7 - Núcleo urbano de Londrina, provavelmente em 1934

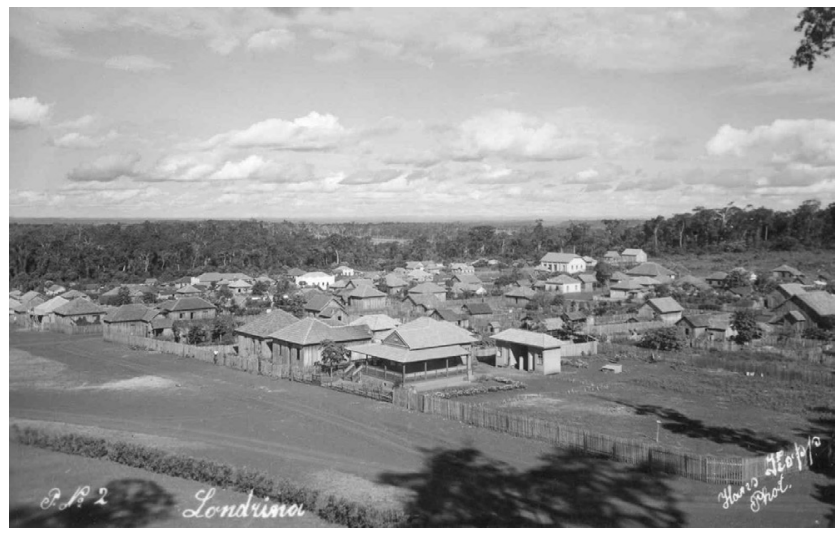

Fotografia: Hans Kopp

Fonte: Acervo do Museu Histórico de Londrina Padre Carlos Weiss

Figura 8 - Vista panorâmica de Londrina, provavelmente em 1935

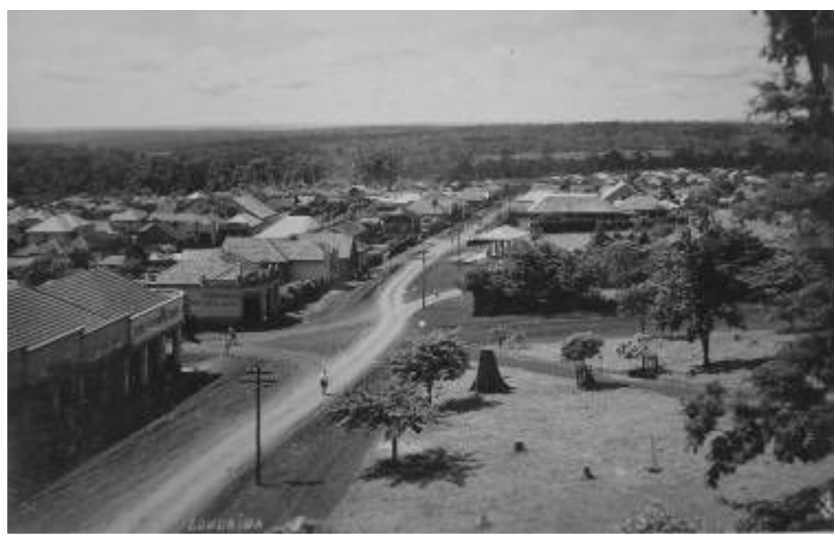

Fotografia: Hans Kopp

Fonte: Acervo do Museu Histórico de Londrina Padre Carlos Weiss

Porém, sem dúvida, o mais produtivo e conhecido fotógrafo contratado pela CTNP para produzir imagens de caráter documental e publicitário do empreendimento foi José Juliani. Vindo do interior de São Paulo, Juliani chegou a Londrina em 11 de março de 1933, então com 37 anos de idade, casado e pai de cinco filhos. Havia aprendido o ofício em Nova Europa (SP), com um fotógrafo alemão, que the vendeu o equipamento ao se aposentar da profissão.

Juliani veio para Londrina para trabalhar como carpinteiro, afinal acreditava que haveria muito mais demanda por construção de casas em um lugar que estava crescendo, que por fotografia em um lugar onde todos estavam interessados em "fazer a vida" e não em preservar a memória. Contudo, montou um estúdio em um "puxadinho" em sua casa e afixou na parede externa um letreiro: Photo Studio. Tão logo havia afixado o letreiro, o acaso começou a trabalhar a seu favor:

Em 1933, o Sr. Ernest Rosemberg, engenheiro da CTNP, precisava de uma fotografia do salto do ribeirão Cambezinho (nome atual), que fica no Parque Arthur Thomas (nome atual) para enviar à Inglaterra. O escritório de Londrina havia solicitado a construção de uma turbina geradora de energia elétrica para viabilizar, num primeiro momento, o fornecimento de eletricidade para o próprio escritório e as casas de seus diretores. Os estudos para o empreendimento estavam sendo desenvolvidos pela matriz, em Londres, que solicitou uma fotografia do salto do ribeirão para saber da viabilidade - ou não - do projeto. (BONI, 2004, p.253).

O fotógrafo que havia sido contratado em São Paulo para fazer esta fotografia não compareceu na data marcada e o engenheiro Rosemberg foi avisado por um auxiliar que, agora, havia um fotógrafo em Londrina. Foram até a casa de José Juliani e pediram para ele fazer o serviço. Ele foi, fez e agradou (Figura 9). A partir de então, a CTNP deixou de buscar fotógrafos em outras cidades e passou a contratar Juliani para suas inúmeras demandas. Neste contexto, é interessante notar a importância de uma fotografia para a solução de uma dúvida: Londres pediu uma fotografia para avaliar a viabilidade ou não de um projeto em Londrina, do outro lado do Oceano Atlântico. 
Figura 9 - Salto do ribeirão Cambezinho, primeiro trabalho de Juliani para a CTNP, em 1933

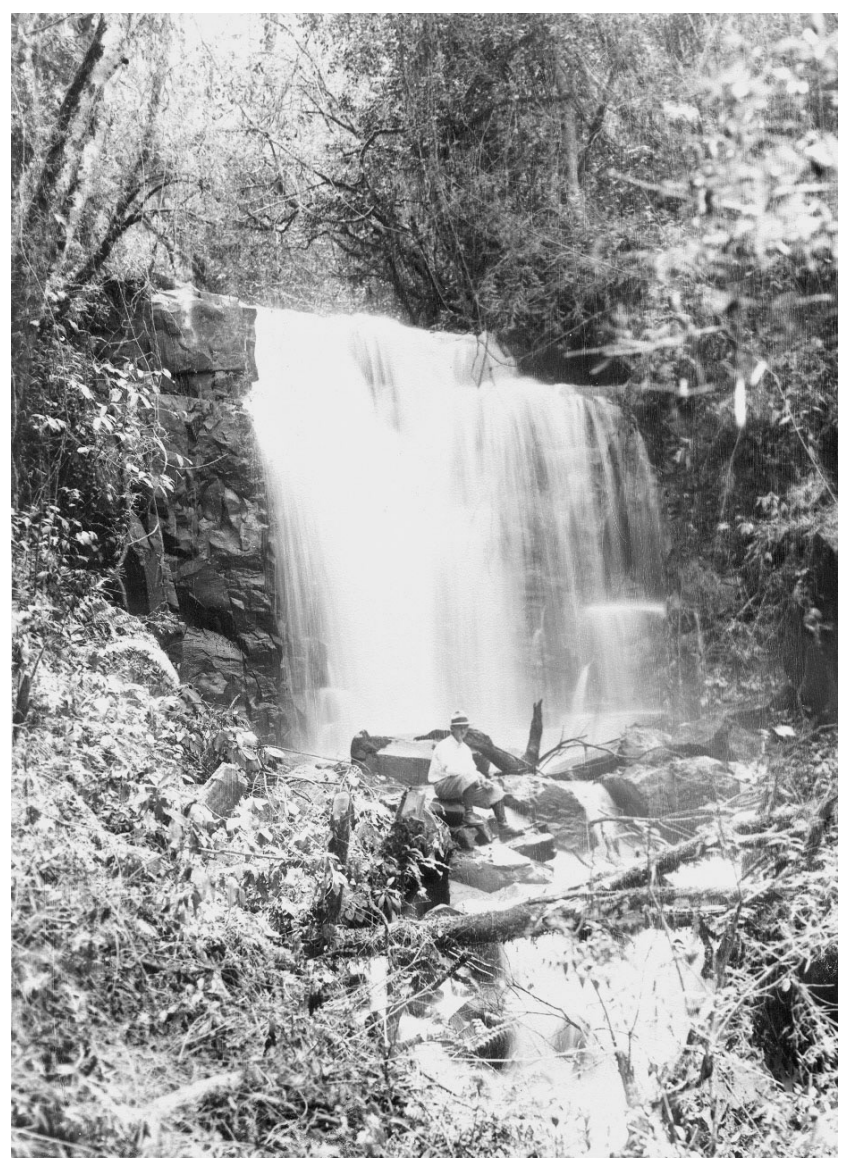

Fotografia: José Juliani

Fonte: Acervo do Museu Histórico de Londrina Padre Carlos Weiss

Nesse momento, Londrina já era um efervescente núcleo urbano. No final de 1934 emancipou-se como município e ganhou autonomia administrativa. Em decorrência dessa conquista política e econômica, várias obras de infraestrutura - parte de caráter público, parte de caráter privado, pois a colonizadora ainda era responsável por serviços essenciais fornecidos à cidade foram contratadas e isso, evidentemente, contribuiria de maneira ainda mais decisiva para o sucesso do empreendimento da CTNP. Em outras palavras, seria prudente documentar toda essa efervescência urbana, econômica e administrativa: inauguração de casas residenciais imponentes, de casas comerciais importantes, de agências bancárias, de hotéis, de serviços coletivos, da organização de segmentos da sociedade, de visitas de políticos e autoridades do estado e do país, enfim tudo o que pudesse ser imageticamente utilizado para a construção do imaginário coletivo de região próspera.

Assim, coube a José Juliani transformar-se, por conta dos serviços prestados à CTNP, no maior fotógrafo documentador das transformações urbanas e rurais de Londrina e do norte do Paraná entre as décadas de 1930 e 1940, seja o crescimento do núcleo urbano (Figura 10), a instalação de novas indústrias (Figura 11) ou a organização política do recém-emancipado município (Figura 12).

Figura 10 - Vista panorâmica de Londrina, provavelmente em 1934

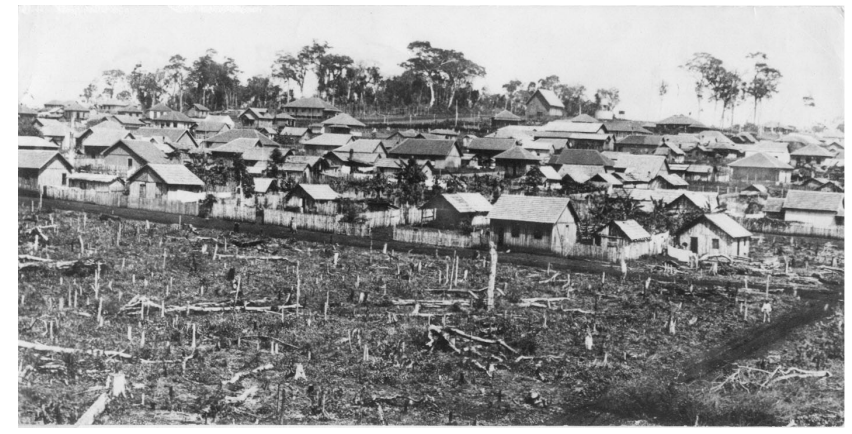

Fotografia: José Juliani

Fonte: Acervo do Museu Histórico de Londrina Padre Carlos Weiss

Figura 11 - Sede de uma nova madeireira, com seus veículos e trabalhadores, em Londrina

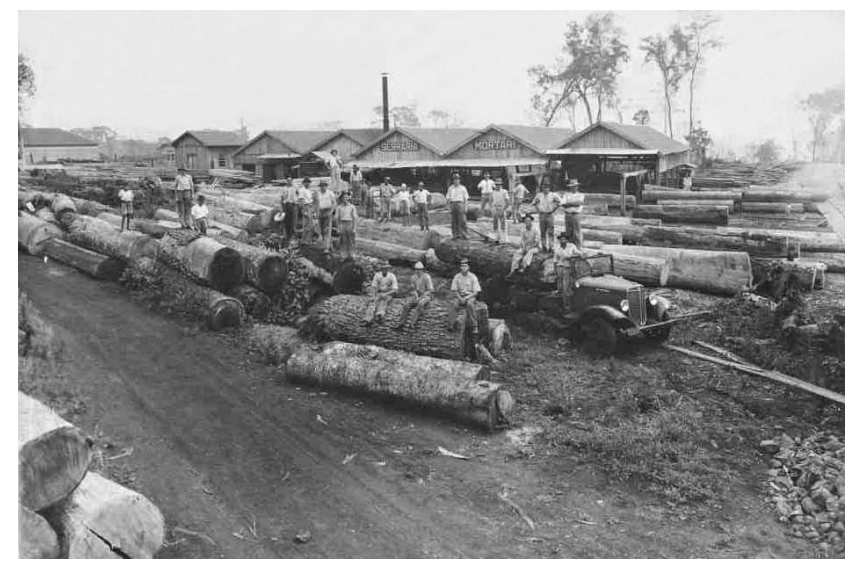

Fotografia: José Juliani

Fonte: Acervo do Museu Histórico de Londrina Padre Carlos Weiss

Figura 12 - Posse do prefeito Willie Davids, em 20 de janeiro de 1936

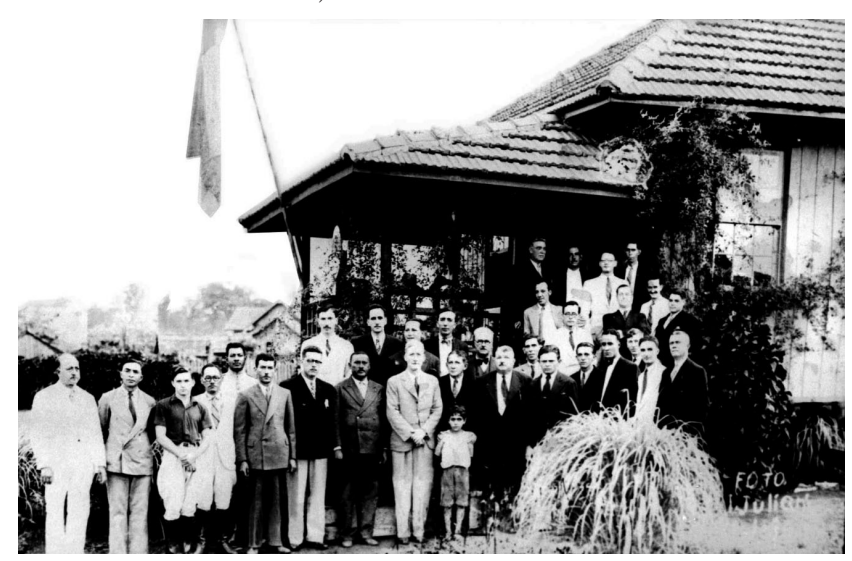

Fotografia: José Juliani

Fonte: Acervo do Museu Histórico de Londrina Padre Carlos Weiss 
O pioneirismo de George Craig Smith em produzir as primeiras imagens de uma região ainda inóspita - na qual seria plantada e edificada a mais importante cidade do norte do Paraná -, para documentar a ocupação e desbravamento do empreendimento da Companhia de Terras Norte do Paraná; a competência de Theodor Preising em produzir as primeiras fotografias de caráter "publicitário" do empreendimento - ousado e pioneiro - para publicizá-lo no Brasil e no mundo; as aventuras de Hans Kopp em produzir imagens panorâmicas "aéreas" e inéditas, do alto de árvores, para documentar o crescimento das cidades no norte paranaense; o profissionalismo de José Juliani em documentar as transformações urbanas e rurais de Londrina e região para aprovação de projetos, relatórios de gestão e publicidade duas décadas da história de Londrina foram de fundamental importância para preservação da memória da cidade e do norte do Paraná e caracterizam o primeiro lance de sorte da fotografia em Londrina.

A vida e obra desses fotógrafos - e suas importantes contribuições para a preservação da memória do norte do Paraná - têm sido continuamente recuperadas graças a esforços desprendidos pela Universidade Estadual de Londrina, seja, por meio de dois de seus programas de pós-graduação, o Mestrado em Comunicação e o Mestrado em História Social, seja por meio de dois de seus órgãos suplementares, o Museu Histórico de Londrina Padre Carlos Weiss e o Centro de Documentação e Pesquisa Histórica (CDPH). E não sem justa causa, pois já é moeda corrente que "a história de Londrina - tanto quanto a história da maioria dos municípios brasileiros, notadamente os fundados a partir de 1840 - não seria tão consistente sem os importantes documentos iconográficos representados pela fotografia". (BONI, 2008, p.108).

Muitas das imagens da Segunda Guerra Mundial, hoje disponíveis, especialmente as dos campos de concentração e do holocausto, foram obtidas porque os alemães eram instruídos a relatar a evolução (e atrocidades) de sua máquina de guerra para prestar contas, por meio de relatórios minuciosamente detalhados e fartamente documentados fotograficamente, de suas ações ao III Reich, em Berlim. A documentação da evolução do empreendimento da CTNP, longe de ser comparada à disciplina alemã de prestação de contas do desenvolvimento da guerra, também foi de fundamental importância para que imagens dos primórdios da região norte do estado do Paraná, especialmente de Londrina, pudessem, hoje, estar disponíveis para estudantes, professores, pesquisadores e historiadores.

\section{Imigração estrangeira: o segundo lance de sor- te de Londrina com a fotografia}

O segundo - e importante - lance de sorte de Londrina com a fotografia deu-se em razão de sua colonização por imigrantes estrangeiros. A CTNP também publicizava seu empreendimento na Europa, onde mantinha escritórios de representação em diversas capitais. A publicidade atingia vários países europeus, notadamente Alemanha, Áustria, Espanha, Itália e Portugal, alguns países do Leste Europeu e do Oriente Médio e, timidamente, a Ásia. Na Ásia, por outras circunstâncias, a oportunidade de compra de terras chamou a atenção dos japoneses. Explica-se: os primeiros compradores de terras no norte do Paraná foram os imigrantes japoneses que já residiam e trabalhavam nas lavouras de café do estado de São Paulo. Suas economias, no entanto, não eram suficientes para comprar um lote de terras no estado vizinho, onde, em razão do elevado nível de desenvolvimento os preços eram muito altos, mas eram, sim, suficientes para comprar um bom pedaço de terras neste novo empreendimento. Foram esses primeiros compradores japoneses os principais responsáveis pela divulgação do projeto no Japão, por meio de correspondências com parentes e amigos.

Nos primeiros anos de sua colonização, de início a meados da década de 1930, o norte do Paraná, recebeu imigrantes de mais de 20 diferentes nacionalidades. Alguns fugiam da pobreza de seus países de origem, muitos fugiam da perseguição que Adolf Hitler havia desencadeado contra os judeus, outros fugiam dos conflitos que estavam por estourar, como a Guerra Civil Espanhola e a Segunda Guerra Mundial. Um relatório da CTNP, com os dados de venda de lotes entre 1930 e 1935 demonstra o predomínio da presença estrangeira na colonização da região (Gráfico 1). 
Gráfico 1 - Venda de lotes de terras pela CTNP de 1930 a 1935

\begin{tabular}{|cc|}
\hline $\begin{array}{l}\text { Número de lotes vendidos pela Companhia de Terras Norte do } \\
\text { Paraná, entre 1930 e 1935, e nacionalidade dos compradores* }\end{array}$ \\
\hline Número de lotes & Nacionalidade / compradores \\
\hline 1266 & Brasileira \\
\hline 479 & Alemã \\
\hline 476 & Italiana \\
\hline 434 & Japonesa \\
\hline 216 & Espanhola \\
\hline 156 & Portuguesa \\
\hline 98 & Polonesa \\
\hline 75 & Húngara \\
\hline 60 & Ucraniana \\
\hline 41 & Tchecoslovaca \\
\hline 32 & Russa \\
\hline 20 & Austríaca \\
\hline 19 & Suíça \\
\hline 15 & Lituana \\
\hline 08 & Romena \\
\hline 06 & Iugoslava \\
\hline 06 & Inglesa \\
\hline Fonte: Relatório de 1935 da CTNP, publicado no jornal Folha de Londrina, de 29 \\
\hline \\
\hline de abril de 1975, em artigo assinado por Antonio Vilela Magalhães. \\
\hline
\end{tabular}

De meados da década de 1930 ao final da década de 1940, em razão da eclosão de grandes conflitos na Europa, inclusive com o envolvimento da Ásia, por um lado, e da paz e prosperidade que o empreendimento britânico representava no norte do Paraná, por outro lado, o número de imigrantes estrangeiros cresceu muito. A CTNP, sabendo da vontade ou da necessidade de emigrar, desenvolvia estratégias para atrair alemães, italianos, japoneses e judeus que desejassem fugir da fome, perseguições e conflitos e se radicarem no norte do Paraná.

Como a emigração de alemães era crescente desde a ascensão de Hitler ao poder, em 1933 - e se acentuou com o início do conflito mundial -, a Alemanha, para evitar o êxodo, proibiu a saída do país com grandes somas em dinheiro ou jóias. Isso, claro, provocou um arrefecimento no processo emigratório. Porém, a CTNP encontrou uma brecha na lei proibitiva e passou a oferecer permuta aos alemães dispostos a vir para o norte do Paraná: eles comprariam - e pagariam - na Alemanha, trilhos e parafusos que a colonizadora precisava para construir a estrada de ferro que cortaria o norte do Paraná no sentido leste-oeste. O valor que os interessados gastassem na compra desses produtos seria transformado em terras no empreendimento. A CTNP se responsabilizava pela retirada e o transporte dessas mercadorias da Alemanha para Londrina. Assim, os alemães poderiam emigrar da Alemanha com o pouquíssimo dinheiro que a lei permitia que, ao chegarem a Londrina, rece- beriam suas terras com os documentos de propriedade devidamente regularizados.

Até a chegada dos estrangeiros, o norte do $\mathrm{Pa}$ raná vinha sendo habitado por pessoas pouco letradas, uma maioria de analfabetos contratada para os trabalhos braçais no campo (derrubada de matas e preparo do solo para o plantio lavouras) ou núcleo urbano (construção civil) das localidades que surgiam. Neste sentido, os estrangeiros representaram um ganho educacional, cultural e profissional para a região, pois vinham de seus países de origem educacionalmente formados, culturalmente talhados e profissionalmente qualificados. Nenhuma estranheza, portanto, em saber que as duas primeiras escolas construídas em Londrina foram as das colônias alemã e a japonesa.

Como os estrangeiros chegavam profissionalmente qualificados, coube a eles o exercício de determinados ofícios hoje conhecidos como prestação de serviços. Entre eles, para a sorte da memória e da história de Londrina e região, o ofício de fotógrafo. Vários fotógrafos estrangeiros se estabeleceram profissionalmente em Londrina e cidades vizinhas, principalmente alemães e japoneses, entre eles Carlos Stender (alemão, estabelecido em Londrina, com o Foto Estrela), Suejiro Yasunaka (japonês, estabelecido em Londrina, sucedeu Carlos Stender no Foto Estrela), Antonio José de Mello (espanhol, estabelecido em Londrina, com o Foto Mello), Mineso Matsuo (japonês, estabelecido em Londrina, com o Foto Nippon), Haruo Ohara (japonês, fotógrafo amador, cujo acervo, hoje, é administrado pelo Instituto Moreira Salles), Arthur Adolpho Eidam (filho de imigrantes alemães, estabelecido em Cambé, com o Foto Arthur), Hans Kopp (austríaco, estabelecido em Rolândia, com o Foto Elegância) e outros que estão sendo pesquisados para a produção de um livro, cujo título será Fotógrafos pioneiros.

O fato de haver fotógrafos estabelecidos em um lugar onde a prioridade era "vencer" ou, no mínimo, "sobreviver" economicamente, foi imprescindível para garantir os registros de família, dos eventos sociais (principalmente festas religiosas e populares, casamentos e formaturas), do cotidiano e do desenvolvimento da cidade (construções, reformas, ampliações, inaugurações). Mesmo produzido sem essa intenção, e de caráter mais individual que coletivo, os registros fotográficos dos primeiros anos do norte do Paraná são, hoje, de suma importância para a recuperação de dados históricos e preservação da memória da região. "A história de Londrina - tanto quanto a história da maioria dos municípios brasileiros, notadamente os fundados a partir de 8140 - não 
seria tão consistente sem os importantes documentos iconográficos representados pela fotografia." (BONI, 2008, p.107).

Esse segundo lance de sorte de Londrina com relação à fotografia - o fato de também haver sido colonizada por imigrantes estrangeiros - ganha relevância se compararmos a riqueza imagética do início de sua colonização (década de 1930) com a pobreza documental de municípios mais recentes, quando as facilidades de fotografar eram muito maiores e os custos muito menores. Alguns municípios do norte do estado de Mato Grosso, como Sinop, Alta Floresta e Sorriso, por exemplo, cerca de 40 anos mais novos que Londrina, possuem muito menos documentos iconográficos de seus primórdios. O motivo? É simples. Eles não foram colonizados com objetivos de fixação de residência pelos compradores de terras, mas sim abertos como expansão das fronteiras agrícolas para exploração comercial. Os investidores chegavam, tomavam posse das terras, desmatavam, preparavam o solo, plantavam, colhiam, vendiam, lucravam, plantavam novamente e assim sucessivamente. Não havia preocupação em gerar registros para a preservação da memória. A prioridade era lucrar. Sinop, por exemplo, é a sigla de Sociedade Imobiliária Norte do Paraná, ou seja, iniciativa de um grupo de agricultores paranaenses interessados em expandir suas fronteiras agrícolas.

\section{Considerações finais}

Londrina, no norte do estado do Paraná, como tantas outras cidades, utiliza a fotografia para recuperar dados históricos, preservar a memória e democratizar os conhecimentos sobre sua história. No entanto, em seu processo de colonização, Londrina passou por duas peculiaridades que podem ser consideradas como lances de sorte da cidade com relação à fotografia.

O primeiro lance de sorte foi a necessidade de a Companhia de Terras Norte do Paraná publicizar o empreendimento imobiliário que deflagrou o processo de colonização no norte do Paraná, para atrair investidores para uma região ainda inóspita. Para tanto, usou fartamente a mídia fotografia como estratégia de publicidade. Neste sentido, e para este intuito, contratou fotógrafos para a produção de fotografias que "vendessem" a seriedade do empreendimento, a sensação de segurança para o investidor (pois todos os documentos estavam judicialmente desembaraçados) e, principalmente, a fertilidade do solo e sua pronta resposta ao plantio de lavouras, com altíssima produtividade. Da produção de fotografias, em um primeiro momento, com finalidade publicitária, res- taram centenas de registros que documentam todas as etapas dos primórdios de Londrina.

O segundo lance de sorte foi a vinda de imigrantes estrangeiros no início de seu processo de colonização. Normalmente fugindo da pobreza, perseguições étnicas ou religiosas, ou de conflitos em seus países de origem, esses imigrantes chegavam com qualificação profissional para o exercício de ofícios específicos, entre eles o da fotografia. Graças a eles, serviços fotográficos sempre foram uma constante em Londrina. Mesmo considerando as especificidades das demandas, mais individuais que coletivas, eles produziram registros familiares e sociais importantíssimos para a recuperação da memória e construção da história da cidade e região.

Esses dois lances de sorte, portanto, contribuíram decisivamente para a produção de farta documentação do início da colonização de Londrina e de outras cidades do norte do estado do Paraná. Muitos desses documentos imagéticos estão disponíveis para pesquisa em instituições públicas, principalmente o Museu Histórico de Londrina Padre Carlos Weiss. Outros tantos estão em processo de higienização, catalogação e digitalização pelo museu e posteriormente também serão disponibilizados. A fotografia tem sido uma mídia fundamental para pesquisadores somarem conhecimentos no processo de construção histórica da cidade de Londrina e da região norte do estado do Paraná.

\section{Referências bibliográficas:}

ARIAS NETO, José Miguel. O Eldorado: representações da política em Londrina 1930-1975. Londrina: Eduel, 1998.

BONI, Paulo César. Fincando estacas! A história de Londrina (década de 30) em textos e imagens. Londrina: Edição do autor, 2004.

BONI, Paulo César. A fotografia como mídia visual da recuperação histórica de Londrina. Domínios da Imagem, Londrina, v.1, n.2, p.107-128, maio/2008.

BONI, Paulo César (Org.). Certidões de nascimento da história: o surgimento de municípios no eixo Londrina - Maringá. Londrina: Planográfica, 2009.

BONI, Paulo César: SATO, Larissa Ayumi. A mídia fotografia como estratégia publicitária da Companhia de Terras Norte do Paraná. In: BONI, Paulo César (Org.). Certidôes de nascimento da história: o surgimento de municí- 
pios no eixo Londrina - Maringá. Londrina: Planográfica, 2009, p.243-267.

POPOLIN, Cássia Maria. Da Austria ao Paraná: a trajetória imagética de Hans Kopp, primeiro fotógrafo de Rolândia (PR). Dissertação (Mestrado em Comunicação) - Universidade Estadual de Londrina, Londrina, 2010, 93p.

Recebido: $13 / 04 / 2013$

Aprovado: 02/05/2013 